Original Article

\title{
Complications Following Comparison of Surgery for Chronic Subdural Hematoma, With and Without Postoperative Drainage Tube
}

\author{
Imran Altaf', Shahzad Shams ${ }^{2}$ \\ ${ }^{1}$ Department of Neurosurgery, Khawja Muhammad Safdar Medical College, Sialkot - Pakistan \\ ${ }^{2}$ Department of Neurosurgery, Mayo Hospital, Lahore - Pakistan
}

\begin{abstract}
Objectives: Chronic subdural hematoma (CSDH) is one of the most common entities treated in neurosurgery. Postoperative subdural drainage employed after burr hole evacuation for treating CSDH reduces recurrence, but whether it leads to increased surgical complications compared to no postoperative drainage is debatable. The present study was designed to assess whether postoperative subdural drainage leads to increased surgical complications following burr hole evacuation of CSDH compared to no drainage.
\end{abstract}

Materials and Methods: The medical records of 69 patients treated with burr hole evacuation for chronic subdural hematoma between July 2013 to April 2014 were retrospectively analyzed. The patients were divided into two groups. In group A patients, postoperative subdural drainage had been employed following burr hole evacuation of CSDH, while in group B patients there was no drainage. The two groups were then compared for the development of surgical complications other than recurrence.

Results: Sixteen patients developed complications. Acute Subdural hematoma formed in 3 patients. There was intraparenchymal drain insertion in 6 patients. An empyema developed in 2 patients, while one patient each developed an Extradural hematoma, fits, contusion, and hemorrhagic infarction. All the complications occurred in the group A patients receiving postoperative subdural drainage. Postoperative subdural drainage tube was found to be significantly associated $(p=0.0017)$ with complications.

Conclusion: We conclude that postoperative subdural drainage following burr hole evacuation of chronic subdural hematoma is associated with increased surgical complications compared to no drainage.

Keywords: Chronic subdural hematoma, burr-hole evacuation, postoperative subdural drainage, complications.

Corresponding Author: Imran Altaf

Department of Neurosurgery

Khawja Muhammad Safdar Medical College

Sialkot - Pakistan

Email: drimr2@hotmail.com
Date of Submission: 12-08-2021

Date of Revision: 19-09-2021

Date of Acceptance: 23-09-2021

Date of Online Publishing: 30-09-2021

Date of Print: 30-09-2021

DOI: $10.36552 /$ pjns.v25i3.589 


\section{INTRODUCTION}

Chronic subdural hematoma (CSDH) is one of the most commonly encountered pathologies in neurosurgery. ${ }^{1-6}$ The incidence of chronic subdural hematoma has been reported in the literature to be as high as 13.1 cases per 100000 population. ${ }^{6}$ Various surgical procedures are utilized for treating this condition that includes twist drill craniostomy, burr hole craniostomy, and craniotomy. ${ }^{7-10}$ Of these surgical modalities, burr hole evacuation with postoperative drainage is the most commonly employed modality for treating $\mathrm{CSDH} .{ }^{11,12}$ Multiple studies comparing postoperative subdural drainage following CSDH evacuation with no drainage concluded that postoperative subdural drainage reduces recurrence but does not lead to increased complications. ${ }^{13-16}$ But in contrast to the results of these studies, studies comparing postoperative subdural drainage with postoperative subgaleal drainage following CSDH evacuation found that subdural drainage is associated with increased complications compared to subgaleal drainage. ${ }^{17-20}$ In subgaleal drainage the drain remains superficial to bone and does not come into contact with brain parenchyma, bridging veins or hematoma membranes and so technically the studies comparing complications of subdural drainage with subgaleal drainage should not showa difference in results from studies comparing subdural drainage with no drainage. However, recent studies have consistently shown contrasting results for these two sets of studies regarding the association of subdural drainage with complications with one set of studies showing increased complications associated with subdural drainage and the other showing no difference in complications when subdural drainage is instituted. ${ }^{13-20}$ The association of postoperative subdural drainage with increased complications thus becomes controversial. The present study was designed to address this controversy, and we decided to compare the complications between patients receiving postoperative subdural drainage after CSDH evacuation and those that did not receive postoperative drainage in our department.

\section{MATERIALS AND METHODS}

\section{Study Design and Setting}

The study was conducted in the department of neurosurgery Lahore. This was a retrospective observational study. Medical records of adult patients that had undergone burr hole evacuation of chronic subdural hematoma from July 2013 to April 2014 were retrospectively analyzed.

\section{Inclusion Criteria}

All the adult patients treated in the department of neurosurgery for chronic subdural hematoma with burr hole evacuation were included in the study.

\section{Exclusion Criteria}

Patients treated with the only craniotomy were excluded from the study.

\section{Diagnosis of Chronic Subdural Hematoma}

The CSDH had been diagnosed on MRI (magnetic resonance imaging) or CT (computed tomography) in all the patients. The CSDH was defined as SDH that was surrounded by a capsule and dark red liquefied blood had been found during surgical evacuation.

\section{Patient Groups and Management Protocol}

We divided the patients into two groups. Group A consisted of patients in whom postoperative subdural drainage had been employed. Group B consisted of patients in whom no drain had been passed. For the patients in whom postoperative subdural drainage had been employed the drain 
was removed within 72 hours. A postoperative CT was obtained in all the patients within 72 hours of surgery. A further CT was done only if the patient deteriorated clinically or the symptoms recurred. Surgical complications apart from recurrence that developed in the operated patients were then studied. These complications included acute subdural hematoma formation, the intraparenchymal passage of drain, empyema formation, postoperative seizures, Extradural hematoma formation, or the development of a postoperative contusion or hemorrhagic infarction. The medical complications were excluded from the study. All the patients were followed for 3 months.

\section{Data Analysis}

The two groups were compared for the development of surgical complications other than recurrences such as hematoma formation, seizures, intraparenchymal drain insertion, postoperative empyema formation, or the development of a postoperative contusion or hemorrhagic infarction. A Chi-square test was then performed to ascertain the clinical significance of the correlation between drain insertion and the development of complications.

\section{RESULTS}

\section{Gender Distribution}

The study included sixty-nine patients. There were 58 males and 11 females.

\section{Age Distribution}

Postoperative subdural drainage had been employed in 47 patients in group A, while the 22 patients in group $B$ did not receive postoperative drainage. The mean age of patients in group $A$ receiving drainage was 62.2 years, and in the group, B was 64.2 years.

\section{Complications of Postoperative Subdural Drainage}

Overall, 16 patients suffered from complications. Three patients developed an acute subdural hematoma. In six patients there was the intraparenchymal insertion of a drain. Two patients developed postoperative empyema. One patient each developed an Extradural hematoma, postoperative fits, contusion, and a hemorrhagic infarction. All the complications occurred in the group A patients receiving postoperative subdural drainage as shown in table 1 . Thus $34 \%$ (16/47) of the patients in the subdural drainage group developed complications. No complication occurred in group B patients where no postoperative drainage had been employed.

\begin{tabular}{|lll|}
\hline \multicolumn{2}{l}{ Table 1: Details of complications. } \\
Complications & Subdural Drain & No Drain \\
Acute Subdural hematoma & $\mathbf{( N = 4 7 )}$ & $\mathbf{( N = 2 2 )}$ \\
Intraparenchymal drain & $6(12.8 \%)$ & 0 \\
Empyema & $3(6.4 \%)$ & 0 \\
Fits & $1(2.1 \%)$ & 0 \\
Extradural hematoma & $1(2.1 \%)$ & 0 \\
Hemorrhagic infarction & $1(2.1 \%)$ & 0 \\
Contusion & $1(2.1 \%)$ & 0 \\
\hline
\end{tabular}

Statistical analysis with an uncorrected Chisquare test showed that the complications were significantly associated ( $p=0.001793)$ with postoperative subdural drainage as shown in Table 2.

Table 2: Statistical association between drainage and complications.

\begin{tabular}{|c|c|c|c|}
\hline & $\begin{array}{c}\text { Subdural } \\
\text { Drain } \\
(\mathrm{N}=47)\end{array}$ & $\begin{array}{l}\text { No Drain } \\
(\mathrm{N}=22)\end{array}$ & $P$ value \\
\hline $\begin{array}{l}\text { Patients developing } \\
\text { complications }\end{array}$ & 16 & 0 & $\begin{array}{c}0.001793 \\
\text { (Significant }\end{array}$ \\
\hline No complications & 31 & 22 & Result) \\
\hline
\end{tabular}




\section{DISCUSSION}

$\mathrm{CSDH}$ is one the most common clinical entities treated surgically in neurosurgery. ${ }^{4-6}$ Recurrence rates are high and range between 5 to $30 \% .{ }^{16,19,21}$ Burrhole evacuation combined with postoperative subdural drainage is the standard, recommended, and most commonly utilized method of treating CSDH. ${ }^{11,19,22}$ Subdural drainage after burrhole evacuation not only reduces recurrence, ${ }^{13-16,23}$ but also improves the survival and functional outcome in patients operated for $\mathrm{CSDH}^{22,23}$

Multiple studies comparing postoperative subdural drainage with no drainage found that not only the recurrence is reduced in the group of patients receiving subdural drainage, but also the surgical complications do not get increased in that group. ${ }^{13-16}$ Recently interest has also arisen in the employment of postoperative subgaleal drainage instead of subdural drainage for treating $\mathrm{CSDH}$. Recent studies comparing subdural with subgaleal drainage concluded that subdural drainage is associated with more complications like iatrogenic parenchymal brain damage, hematoma formation, and subdural empyema as compared to subgaleal drainage. ${ }^{17-20}$ The topic of association between subdural drainage and increased surgical complications thus becomes controversial in the light of contrasting results of these studies.

The present study was conducted to ascertain whether postoperative subdural drainage is associated with increased complications compared to no drainage. In our study 16 complications occurred, all of them in the subdural drainage group. The complication rate was $34 \%$. Comparing our complication rate with the studies that have studied the complications of subdural drainage following burrhole evacuation of $\mathrm{CSDH}$, we found that our surgical complication rate of $34 \%$ was high as compared to the complication rates of $8-26 \%$ documented in those studies. ${ }^{1,17,18}$ But what was striking was that no complication occurred in the 22 patients in our study in whom no drainage had been instituted.
We found the surgical complications to be significantly associated ( $p=0.001793)$ with postoperative subdural drainage. This is in contrast to the studies that had concluded that subdural drainage does not lead to increased complications when compared to no drainage ${ }^{13-16}$ and more in line with the findings of those studies that had found subdural drainage to be associated with increased complications when compared to subgaleal drainage. ${ }^{17-20}$ We thus conclude that postoperative subdural drainage is associated with increased complications compared to no drainage.

\section{Limitations of the study}

Our study is a small, single-center, retrospective study. Furthermore, we did not compare the medical complications of the drainage and no drainage group. Further research into the matter with a prospective study consisting of larger sample size is required to accomplish the true relationship between subdural drainage and surgical complications following chronic subdural hematoma evacuation.

\section{Ethics Committee Approval}

As our study is retrospective so ethical committee approval was not required.

\section{CONCLUSION}

Our study concludes that following burr hole evacuation of chronic subdural hematoma, postoperative subdural drainage is associated with increased complications compared to no drainage.

\section{REFERENCES}

1. Hyun Seok Lee, Sang Woo Song, Young II Chun, Woo Jin Choe, Joon Cho, Chang Taek Moon, and Young-Cho Koh. Complications Following Burr Hole Craniostomy and Closed-System Drainage for 
Subdural Lesions. Korean J Neurotrauma, 2018; 14 (2): 68-75.

2. Minna Rauhala, Pauli Helén, Heini Huhtala, Paula Heikkilä, Grant L. Iverson, Tero Niskakangas, Juha Öhman and Teemu M. Luoto. Chronic subdural hematoma-incidence, complications, and financial impact. Acta Neurochir (Wien), 2020; 162 (9): 2033-2043.

3. Fernand Nathan Imoumby, Franck Kouakou, Yao C. Hugues Dokponou, Abad Cherif El Asri, Miloud Gazzaz. Brain Stroke as a Post-Operative Lethal Complication of a Bilateral Chronic Subdural Hematoma: A Case Report. Open Journal of Modern Neurosurgery, 2021; 11 (2): 122-127.

4. Tetsuhisa Yamada, Yoshihiro Natori. Evaluation of Seizures in Patients with Chronic Subdural Hematoma Treated by Burr-Hole Surgery and Risk Factors for Seizures. Int J Brain Disord Treat. 2017; 3 (1): 1-8.

5. Liu W, Bakker NA, Groen RJ. Chronic subdural hematoma: a systematic review and meta-analysis of surgical procedures. J Neurosurg. 2014; 121 (3): 665-73.

6. Lee JM, Park JC, Kim JH. Retrospective analysis of risk factors for recurrent chronic subdural hematoma. Nerve. 2016; 2 (2): 54-58.

7. Jeong SI, Kim SO, Won YS, Kwon YJ, Choi CS. Clinical Analysis of Risk Factors for Recurrence in Patients with Chronic Subdural Hematoma Undergoing Burr Hole Trephination. Korean J Neurotrauma, 2014; 10 (1): 15-21.

8. Kim DH, Kim HS, Choi HJ, Han IH, Cho WH, Nam $\mathrm{KH}$. Recurrence of the Chronic Subdural Hematoma after Burr-Hole Drainage with or without Intraoperative Saline Irrigation. Korean J Neurotrauma, 2014; 10 (2): 101-105.

9. Ko BS, Lee JK, Seo BR, Moon SJ, Kim JH, Kim SH. Clinical Analysis of Risk Factors Related to Recurrent Chronic Subdural Hematoma. J Korean Neurosurg Soc. 2008; 43 (1): 11-15.

10. Escosa Baé M, Wessling $H$, Salca $H C$, de Las Heras Echeverría P. Use of twist-drill craniostomy with drain in evacuation of chronic subdural hematomas: independent predictors of recurrence. Acta Neurochir (Wien), 2011; 153 (5): 1097-103.

11. Soleman J, Kamenova M, Lutz K, Guzman R, Fandino J, Mariani L. Drain Insertion in Chronic Subdural Hematoma: An International Survey of
Practice. World Neurosurg. 2017; 104: 528-536.

12. Rohde V, Graf G, Hassler W. Complications of burrhole craniostomy and closed-system drainage for chronic subdural hematomas: a retrospective analysis of 376 patients. Neurosurg Rev. 2002; 25 (1-2): 89-94.

13. Santarius $T$, Kirkpatrick PJ, Ganesan D, Chia HL, Jalloh I, Smielewski $P$, et al. Use of drains versus no drains after burr-hole evacuation of chronic subdural haematoma: a randomised controlled trial. Lancet. 2009; 374 (9695): 1067-73.

14. Peng $D$, Zhu $Y$. External drains versus no drains after burr-hole evacuation for the treatment of chronic subdural haematoma in adults. Cochrane Database Syst Rev. 2016; 2016 (8): CD011402.

15. Singh AK, Suryanarayanan B, Choudhary A, Prasad A, Singh S, Gupta LN. A prospective randomized study of use of drain versus no drain after burrhole evacuation of chronic subdural hematoma. Neurol India, 2014; 62 (2): 169-74.

16. Dhanapal Pattanam Velappan, Ponnaiyan Natesan Palaniappan, Anbarasi Pandian A prospective randomized study of use of drain versus no drain after burr-hole evacuation of chronic subdural hematoma. Int Surg J. 2018; 5 (6): 2304-2307.

17. Chih AN, Hieng AW, Rahman NA, Abdullah JM. Subperiosteal Drainage versus Subdural Drainage in the management of Chronic Subdural Hematoma (A Comparative Study). Malays J Med Sci. 2017; 24 (1): 21-30.

18. Soleman J, Lutz $K$, Schaedelin S, Kamenova $M$, Guzman R, Mariani L, Fandino J. Subperiosteal vs Subdural Drain After Burr-Hole Drainage of Chronic Subdural Hematoma: A Randomized Clinical Trial (cSDH-Drain-Trial). Neurosurgery, 2019; 85 (5): E825-E834.

19. Häni L, Vulcu $S$, Branca $M$, Fung $C$, Z'Graggen WJ, Murek $M$, et al. Subdural versus subgaleal drainage for chronic subdural hematomas: a post hoc analysis of the TOSCAN trial. J Neurosurg. 2019: 19.

20. Kaliaperumal C, Khalil A, Fenton E, Okafo U, Kaar G, O'Sullivan M, Marks C. A prospective randomised study to compare the utility and outcomes of subdural and subperiosteal drains for the treatment of chronic subdural haematoma. Acta Neurochir (Wien), 2012; 154 (11): 2083-8; Discussion 2088-9. 
21. Cofano F, Pesce A, Vercelli G, Mammi M, Massara A, Minardi $M$, et al. Risk of Recurrence of Chronic Subdural Hematomas After Surgery: A Multicenter Observational Cohort Study. Front Neurol. 2020; 11: 560269.

22. Guilfoyle MR, Hutchinson PJ, Santarius T. Improved long-term survival with subdural drains following evacuation of chronic subdural haematoma. Acta Neurochir (Wien), 2017; 159 (5): 903-905.

23. Alcalá-Cerra G, Young AM, Moscote-Salazar LR, Paternina-Caicedo A. Efficacy and safety of subdural drains after burr-hole evacuation of chronic subdural hematomas: systematic review and meta-analysis of randomized controlled trials. World Neurosurg. 2014; 82 (6): 1148-57.

\section{Additional Information}

Disclosures: Authors report no conflict of interest.

Ethics committee approval: As our study was retrospective so ethical committee approval was not required.

Human Subjects: Consent was obtained by all patients/participants in this study.

Conflicts of Interest:

In compliance with the ICMJE uniform disclosure form, all authors declare the following:

Financial Relationships: All authors have declared that they have no financial relationships at present or within the previous three years with any organizations that might have an interest in the submitted work.

Other Relationships: All authors have declared that there are no other relationships or activities that could appear to have influenced the submitted work.

\section{AUTHORS CONTRIBUTIONS}

\begin{tabular}{|l|l|l|}
\hline Sr.\# & Author's Full Name & Intellectual Contribution to Paper in Terms of: \\
\hline 1. & Imran Altaf & Study design and methodology. \\
\hline 2. & Imran Altaf & Paper writing and data calculations. \\
\hline 3. & Imran Altaf & Data collection and calculations. \\
\hline 4. & Imran Altaf & Analysis of data and interpretation of results etc. \\
\hline 5. & Imran Altaf & Literature review and referencing. \\
\hline 6. & Shahzad Shams & Analysis of data and quality insurer. \\
\hline
\end{tabular}

